\title{
LENTIBULARIACEAE NO PARQUE ESTADUAL DO IBITIPOCA, MINAS GERAIS, BRASIL
}

\author{
BEATRIZ SETTE E CAMARA DE ANDRADE \& RAFAELA CAMPOSTRINI FORZZA
}

\author{
Jardim Botânico do Rio de Janeiro, Rua Pacheco Leão 915, 22460-30 - Rio de Janeiro, RJ, Brasil. \\ rafaela@jbrj.gov.br
}

\begin{abstract}
Lentibulariaceae in the Ibitipoca State Park, Minas Gerais, Brazil). The Ibitipoca State Park (Parque Estadual do Ibitipoca - PEIB) is inserted in the complex Mantiqueira in the areas of Atlantic forest in the municipality of Lima Duarte, Minas Gerais. It has an area of 1,488 ha with rugged topography ranging from 1,200 to $1,784 \mathrm{~m}$ elevation and humid mesothermal climate with warm summers and dry winters. The vegetation consists of a mosaic, including, besides the rocky fields, tropical rain forests, seasonal and nebular. PEIB were found in 12 species: Genlisea aurea, G. violacea, Utricularia amethystina, U. laciniata, U. nana, U. neottioides, U. nervosa, U. praelonga, U. pubescens, U. pusilla, U. reniformis and U.triloba. All are found in marshy places among mosses and grasses or within the margin of streams. U. reniformis is the most common species in the Park, but is the only one not mentioned in other surveys conducted in areas of rocky fields of Espinhaço. Identification key, descriptions, comments and illustrations are provided.
\end{abstract}

Key words: Atlantic forest, flora, Utricularia, Genlisea

\begin{abstract}
Resumo - (Lentibulariaceae no Parque Estadual do Ibitipoca, Minas Gerais, Brasil). O Parque Estadual do Ibitipoca está inserido no complexo da Mantiqueira, nos domínios da Floresta Atlântica, no município de Lima Duarte, Minas Gerais. Possui uma área de 1.488 ha com relevo escarpado variando de 1.200 a $1.784 \mathrm{~m}$ de altitude e clima mesotérmico úmido, com verões amenos e invernos secos. A vegetação é formada por um mosaico, incluindo, além dos campos rupestres, florestas ombrófila, estacional e nebular. $\mathrm{Na}$ área foram registradas 12 espécies de Lentibulariaceae: Genlisea aurea, G. violacea, Utricularia amethystina, U. laciniata, $U$. nana, U. neottioides, U. nervosa, U. praelonga, U. pubescens, U. pusilla, U. reniformis e U. triloba. Todas as espécies são encontradas em locais brejosos entre musgos e gramíneas, às margens ou dentro de riachos. $U$. reniformis é a espécie mais frequente no parque, porém é a única não citada em outros inventários realizados em áreas de campos rupestres da Cadeia do Espinhaço. São apresentadas chave de identificação, descrições, comentários e ilustrações.
\end{abstract}

Palavras chave: Campo rupestre, Mata Atlântica, flora, Utricularia, Genlisea

\section{Introdução}

Lentibulariaceae é uma família cosmopolita, abrigando três gêneros e cerca de 325 espécies, distribuídas nos gêneros Utricularia (ca. 220 spp.), Genlisea (ca. 25 spp.) e Pinguicula (ca. 90 spp.) (Barthlott et al. 2004, Fischer et al. 2004, Fleischmann et al. 2011). No Brasil, são registradas 83 espécies, sendo 69 de Utricularia e 14 de Genlisea (Miranda \& Rivadavia 2012). Para os campos rupestres, principalmente da Cadeia do Espinhaço, alguns estudos já foram realizados enfocando a família. Para a florula do Mucugê (BA), Harley \& Simmons (1986) registraram 10 espécies; para a Serra do Cipó (MG), Fromm-Trinta (1996) citou 18; no Pico das Almas (BA), Cheek \& Taylor (1995) registraram 17; em Grão Mogol, Fromm-Trinta (2004) registrou 10 espécies; na Flora de Catolés (BA), Taylor (2003), citou 15; e para a Serra de São José (MG) Silva et al. (2011), relataram 13 espécies. Apesar destes estudos, nenhum inventário foi publicado para áreas da Serra da Mantiqueira, e pouco se conhece sobre esta família nas áreas campestres do Domínio Atlântico.

O Parque Estadual do Ibitipoca (PEIB) é uma pequena Unidade de Conservação situada no complexo da Mantiqueira no Domínio da Floresta Atlântica (CETEC 1983) e nos últimos anos, o número de turistas que visitaram 0 parque cresceu aproximadamente 500\%. Em 1988 a área recebeu 7.632 visitantes e atualmente, o número chega a 40.000 pessoas por ano (Administração do PEIB). Em sua área são encontradas muitas cachoeiras, paredões e locais de extrema beleza cênica, somadas a uma vegetação de pequeno porte que viabiliza a abertura de trilhas, e a execução de caminhadas ecológicas com esforço físico relativamente baixo. $\mathrm{O}$ elevado número de turistas e a abertura de novas trilhas têm acarretado diversos problemas como erosão, desmoronamentos e deslizamentos nas encostas, coleta predatória de espécies vegetais com apelo visual e degradação da comunidade vegetal (Salimena 2000).

Se por um lado, vários estudos já foram publicados para as serras da Cadeia do Espinhaço, por outro as vegetações campestres do Domínio Atlântico carecem de monografias que tratem da família. Assim, o presente trabalho tem por objetivo ampliar o conhecimento das Lentibulariaceae, apresentando um estudo sobre uma área de campo rupestre disjunta da Cadeia do Espinhaço e inserida 
no Domínio Atlântico. Além disto, trabalhos de floras locais são de extrema importância para subsidiar políticas de conservação de UCs.

\section{Material e Métodos}

O Parque Estadual do Ibitipoca situa-se no sudeste de Minas Gerais nos municípios de Santa Rita

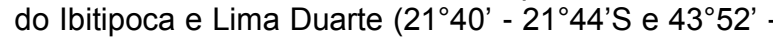
$\left.43^{\circ} 55^{\prime} \mathrm{W}\right)$. Abrange aproximadamente 1.488 ha da Serra de Ibitipoca, que pertence ao Complexo da Mantiqueira (CETEC 1983). O relevo é escarpado com altitudes que variam de 1.200 a $1.784 \mathrm{~m}$ e, segundo a classificação de Koppen, o clima é Cwb, isto é, mesotérmico úmido com invernos secos e verões amenos. A precipitação anual média fica em torno de $1.532 \mathrm{~mm}$ e a temperatura anual média é de 18,9 C (CETEC 1983). A vegetação do Parque é um mosaico de comunidades singular, que abriga florestas ombrófila, estacional e nebular e campos rupestres, que cobrem cerca de $70 \%$ da área. Como consequência desta união de tipos vegetacionais tão distintos, a região congrega espécies típicas da Floresta Atlântica médio e altomontana, da Cadeia do Espinhaço e do cerrado (Salimena 2000). Para maiores detalhes sobre o Parque ver Menini Neto et al. (2007a, b).
O levantamento das espécies presentes no PEIB foi realizado através de coletas em diversos tipos vegetacionais do local de estudo. Além das coletas, foram consultadas as coleções dos herbários: CESJ, GUA, HB, R, RB, RFA e SPF (acrônimos segundo Holmgren et al. 1990). As descrições foram elaboradas a partir dos materiais procedentes do parque utilizando-se as terminologias propostas por Taylor (1989), Font Quer (1989) e Stearn (1992). Utilizou-se material de outras localidades apenas quando os espécimes de lbitipoca foram insuficientes.

\section{Resultados e Discussão}

Foram registradas no PEIB 12 espécies, todas encontradas em locais brejosos entre musgos e gramíneas, margem ou dentro de riachos, sempre em solos pobres em nutrientes. U. reniformis é a espécie mais frequente no parque, porém é a única não citada em outros inventários realizados em áreas de campos rupestres da Cadeia do Espinhaço, sendo comum nos tanques de bromélias dos inselbergues e nos campos de altitude da Floresta Atlântica. Grande parte das espécies registradas parece ter populações muito pontuais no PEIB e algumas são conhecidas por apenas um registro na área.

1. Cálice 5-lobado

1. Genlisea

2. Corola amarela; pedicelo ereto no fruto; cápsula com deiscência circunscisa

2'. Corola roxa; pedicelo reflexo no fruto; cápsula com deiscência longitudinal 1.2. G. violacea

1'. Cálice 2-lobado

3. Brácteas basifixas.

4. Corola alva ou amarela.

5. Margem das sépalas inteira; corola ca. $5 \mathrm{~mm}$ compr.

2.3. U. nana

5'. Margem das sépalas fimbriada, dentada ou erosa; corola $1-1,5 \mathrm{~cm}$ compr

2.6. U. praelonga

4'. Corola roxa.

6. Escamas fimbriadas, e apenas na base do escapo; sépalas de margem fimbriada, dentada ou erosa.....

6'. Escamas inteiras, ao longo de todo escapo; sépalas de margem inteira.

7. Folhas espatuladas; bractéolas conatas à bráctea

2.1. U. amethystina

7'. Folhas reniformes ou cordiformes; bractéolas livres

2.8. U. reniformis

3'. Brácteas basisolutas.

8. Folhas filiformes; corola amarela.

9. Lobos do cálice com ápice agudo, nervuras proeminentes, atingindo a margem 2.10. U. triloba

9'. Lobos do cálice com ápice arredondado, nervuras impressas, não atingindo a margem.

10. Erva $10-36 \mathrm{~cm}$ alt.; corola com mais de $1 \mathrm{~cm}$ compr.

10 . Erva $3-9 \mathrm{~cm}$ alt.; corola até $1 \mathrm{~cm}$ compr.

2.9. U. subulata

8'. Folhas não filiformes; corola roxa, alva ou creme.

11. Folhas peltadas partindo do estolão; corola roxa

11'. Folhas capilares partindo dos estolões e das axilas das escamas inferiores do escapo; corola alva ou creme 
Lentibulariaceae no Parque Estadual do Ibitipoca, Minas Gerais

\section{Genlisea A.St.-Hil.}

Genlisea contém cerca de 25 espécies distribuídas na área tropical das Américas e África (Barthlott et al. 2004, Fischer et al. 2004, Fleischmann et al. 2011). No Brasil, ocorrem 14 espécies, sendo nove endêmicas (Taylor 1991, Miranda \& Rivadavia 2012). Fromm-Trinta (1977) separou as espécies ocorrentes no Brasil em duas seções: Genlisea e Tayloria, de acordo principalmente com deiscência do fruto. Na primeira seção, estão incluídos os táxons com frutos de deiscência circunscisa e na segunda seção os que possuem deiscência longitudinal. A coloração da corola, a pilosidade das estruturas vegetativas e reprodutivas, o pedicelo ereto ou decumbente no fruto são caracteres importantes para a separação das espécies.

1.1. Genlisea aurea A.St.-Hil., Voy. distr. Diam. 2: 429. 1833.

Fig. 1. a-e

Erva, $9-30 \mathrm{~cm}$ alt. Folhas rosuladas, mucilaginosas; lâmina foliar 0,5-2,3 X 0,4-0,7 cm, espatulada. Escapo 1-2 mm diâm., cilíndrico, tricomas simples e glandulosos desde a base, densos no ápice, tornando-o tomentoso, raramente com tricomas nãoglandulosos, esparsos; escamas, ao longo de todo o escapo, lanceoladas, ápice agudo, 2-3,5 mm compr., face abaxial pilosa, tricomas simples e glandulosos: brácteas 1,2-2,5 $\mathrm{mm}$ compr., oval, face abaxial tomentosa, tricomas simples e glandulosos; bractéolas 2, 1-2 mm compr., lanceoladas, face abaxial pilosa, tricomas glandulosos. Inflorescência racemosa, simples, 2-10 flores. Flores com pedicelo ereto, 1-5 mm compr., cilíndrico, hirsutíssimo; lobos do cálice 2-4 $\mathrm{mm}$, ovais, ápice agudo, pilosos na face abaxial, tricomas simples e glandulosos; corola amarela; lábio superior inteiro, ca. $8 \mathrm{~mm}$ compr., oval; lábio inferior 3lobado, face abaxial pilosa, lobos não inteiramente separados, lobo mediano ca. $1 \mathrm{~cm}$ compr. e laterais 0,6 cm compr.; calcar ca. $1 \mathrm{~cm}$ compr., cônico, ápice obtuso, hirsutíssimo, maior ou igual ao lábio inferior da corola; ovário densamente tomentoso; lábio superior do estigma reduzido, inferior orbicular. Fruto cápsula, 3-6 mm diam., piloso, tricomas glandulosos, pedicelo ereto, deiscência circunscisa.

Material examinado: Ibitipoca, 2.X.1970, fl. e fr., L. Krieger s.n. (CESJ 9474).

Material adicional: Minas Gerais. Itacolomy, s.d., fl., L. Damazio et al. s.n. (RB 112381); Santana do Riacho, Serra do Cipó, km 107-108, 17.VIII.1977, fl., G. Martinelli \& A. Távora 2667 (RB); idem, km 125, 19.VII.1950, fl. e fr., A.P. Duarte 2752 (RB); Serra da Bocaina, 7.XII.1952, fr., $F$. Markgraf \& A.P. Duarte 10431 (R, RB, SPF).

Genlisea aurea é endêmica do Brasil, ocorrendo em Tocantins, Bahia, Mato Grosso, Goiás,
Minas Gerais, Espírito Santo, São Paulo, Rio de Janeiro, Paraná e Santa Catarina, em altitudes que variam entre 800 e 2.650 metros (Fromm-Trinta, 1979, Miranda \& Rivadavia 2012). Habita pântanos nas altas montanhas, lajes úmidas, brejos turfosos em campos úmidos, margens de riachos, terrenos arenosos e florestas de galeria (Fromm-Trinta 1996). No PEIB foi coletada somente em 1970 e no material não consta nenhuma descrição precisa da localidade. Floresce e frutifica 0 ano inteiro, porém variações altitudinais e climáticas podem alterar esse padrão (Fromm-Trinta, 1979).

1.2. Genlisea violacea A.St.-Hil., Voy. distr. Diam. 2: 431.1833.

Fig. 1. $f-i ; 4$ e-f

Erva 7,5-28 cm alt. Folhas rosuladas; lâmina foliar 1,5-3,5 X 0,3-0,5 cm, verde com base alva, espatulada. Escapo verde, cilíndrico, 1-1,5 cm diâm., piloso, tricomas simples e glandulosos, esparsos na base a hirsutíssimo no ápice; escamas ausentes ou raro presentes, 1-2, 1-2 mm compr., lanceoladas, face abaxial pilosa, tricomas glandulosos; brácteas 1-2 mm compr., lanceoladas, face abaxial pilosa, tricomas glandulosos; bractéolas 2, 0,5-2 mm compr., livres até a base, lineares, face abaxial pilosa, tricomas glandulosos. Inflorescência racemosa, simples, 2-9 flores. Flores com pedicelo ereto, 0,8-2,5 $\mathrm{mm}$ compr., piloso, tricomas glandulosos; lobos do cálice verdes, 1,5-2,5 $\mathrm{mm}$ compr., lanceolados, hirsutíssimos, tricomas glandulosos; corola roxa, glabra; lábio superior profundamente 2-lobado, lobos ca. $3 \mathrm{~mm}$ compr., arredondados, giba com mácula amarela; inferior profundamente 3-lobado, lobos oblongos, afastados, lobo mediano ca. $1 \mathrm{~cm}$ compr. e os laterais ca. $6 \mathrm{~mm}$ compr.; calcar 4-6 mm compr., menor que lábio inferior, cilíndrico, ápice dilatado, tricomas glandulosos esparsos; ovário tomentoso, tricomas glandulosos; lábios superior e inferior do estigma ovais, reduzidos. Fruto cápsula, 2-3 mm diâm., tomentoso, tricomas glandulosos, pedicelo reflexo, deiscência longitudinal.

Material examinado: 3.X.1970, fl. e fr., D. Sucre et al. 7280 (RB); 30.IX.1970, fl., U. Confúcio s.n. (CESJ 9385); 25.II.1977, fl. e fr., L. Krieger s.n. (CESJ 14596, RB); 5.V.1952, fl. e fr., L. Krieger s.n. (CESJ 16538); 23.IX.2001. fl., F. Rivadavia 1322 (SPF); subida para o Pico do Pião, 10.III.2004, fl. e fr., R.C. Forzza et al. 3096 (K, MBM, NY, RB); trilha Monjolinho-Pião, 28.X.2004, fl. e fr., R.C. Forzza et al. 3598 (K, RB, SPF); 26.II.2005, fl. e fr., F. Rivadavia 1952 (SPF); base do Pico do Pião, 18.IX.2007, fl. e fr., B. SetteCamara et al. 1 (RB).

Genlisea violacea é endêmica do Brasil, ocorrendo em Minas Gerais, Espírito Santo e São Paulo, podendo ser encontrada em locais úmidos nos campos rupestres, brejos, às margens de riachos ou em rochedos úmidos, numa altitude variável entre 399- 

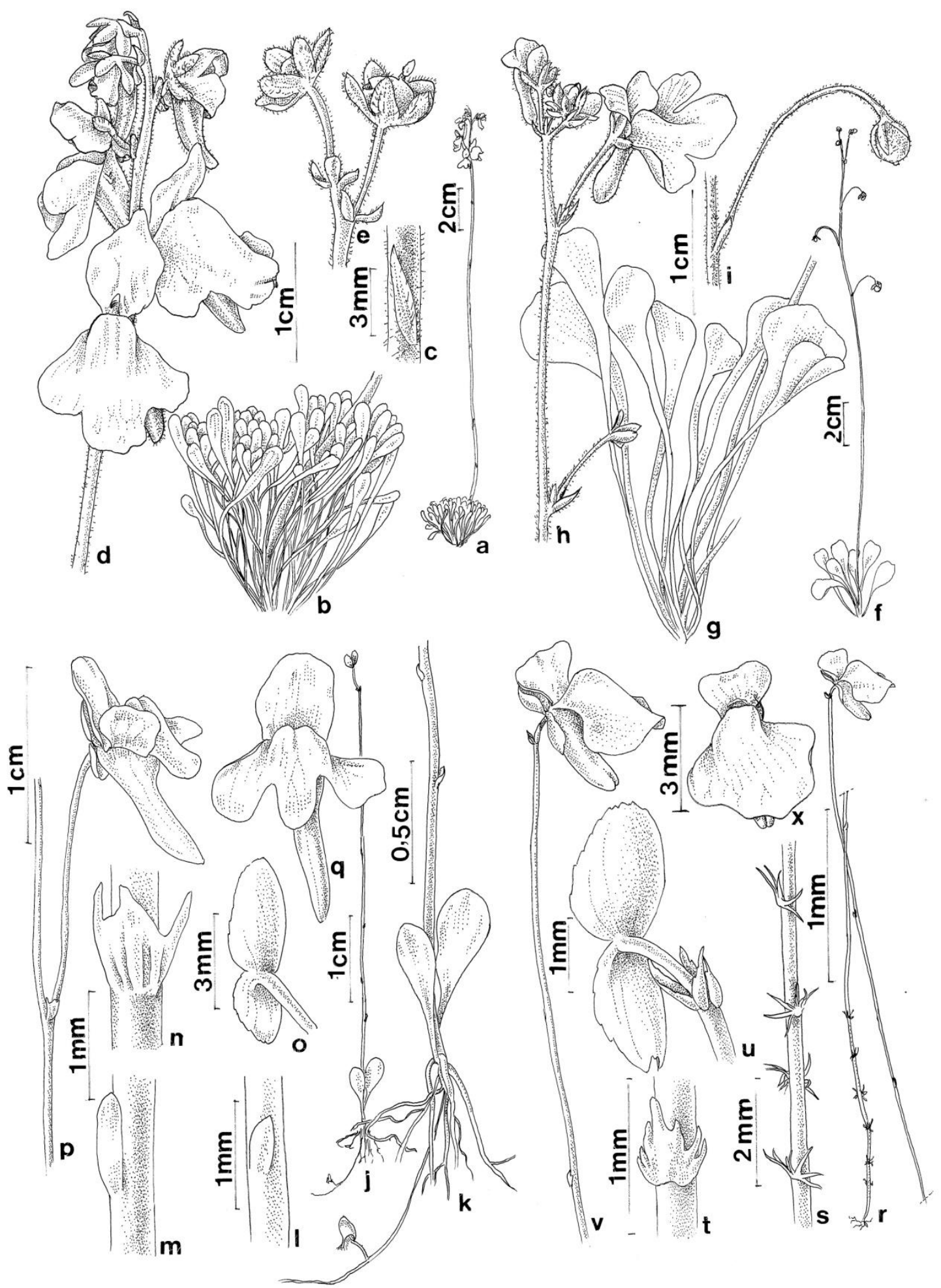

Fig. 1. a-e. Genlisea aurea. a. Hábito. b. Folhas. c. Escama. d. Inflorescência. e. Detalhe das brácteas, bractéolas, cálice e fruto. f-i. G. violacea. f. Hábito. g. Folhas. h. Inflorescência, detalhe das brácteas e bractéolas. i. Fruto. j-q. Utricularia amethystina. j. Hábito. k. Folhas, rizoides e utrículo. I. Escama basal. m. Escama superior. n. Bractéolas conatas à bráctea. 0 . Cálice. p. Corola - vista lateral. q. Corola em vista frontal. r-x. U. laciniata r. Hábito. s. Escamas basais. t. Escama superior. u. Bráctea, bractéolas e cálice. v. Corola em vista lateral. x. Corola - vista frontal. (a-e Krieger s.n. CESJ 9747; f-i Sette-Camara 1; j-q Forzza 2698; r-x Forzza 2668). 
Lentibulariaceae no Parque Estadual do Ibitipoca, Minas Gerais

2.000 metros (Fromm-Trinta 1979, Fleischmann et al. 2011, Miranda \& Rivadavia 2012). No PEIB é encontrada em solos arenosos, entre Sphagnum, sobre pedras úmidas. Diferente das outras espécies de Genlisea que possuem sua floração estendida por todo ano, esta espécie floresce e frutifica de janeiro a julho (Fromm-Trinta 1979).

\section{Utricularia L.}

Utricularia abriga aproximadamente 220 espécies (Barthlott et al. 2004, Fischer et al. 2004) de hábito bem variado, podendo ser terrestres, aquáticas fixas ou flutuantes, reófitas, litófitas ou epífitas. Possui ampla distribuição, ocorrendo em quase todo o mundo, com exceção dos pólos, regiões áridas e ilhas oceânicas. A grande maioria das espécies é encontrada em regiões tropicais e subtropicais (Taylor, 1989). No Brasil, ocorrem 69 espécies, sendo 20 endêmicas (Miranda \& Rivadavia 2012).

2.1. Utricularia amethystina Salzm. ex A.St.-Hil. \& Girard, Compte Rend. Hebd. Séances Acad. Sci. 7: 870. 1838.

Fig. 1. j-q

Erva 10-12 cm alt. Folhas 1-1,5 x 0,5 cm, espatuladas, glabras, formando roseta basal. Escapo glabro, ereto, 0,5-0,8 mm diam., verde a marrom in sicco. Escamas inteiras basifixas, ovais, ápice agudo ou subagudo, escamas da porção basal ca. 0,5 mm compr. e escamas da porção mediana ca. 1 x 0,5 mm. Brácteas basifixas, deltoides, glabras, 3-partidas, com ápice agudo, lacínio mediano 0,8-1 mm compr. e lacínios laterais $0,3-1 \mathrm{~cm}$ compr. Inflorescência ereta, simples, ou ramificada, 1-flora. Flores roxas solitárias, giba alva ou amarela, pedicelo ereto, 1-2,5 cm compr., cálice inteiro verde, com extremidades enegrecidas in sicco, lobos desiguais, côncavos, o superior maior, 3-4 x 1,5 mm, ovado, ápice agudo, o menor, $2 \times 1 \mathrm{~mm}$, largamente ovado, ápice ligeiramente bifurcado; corola de margem inteira, ca. 1,4-1,6 cm compr., lábio superior oblongo, ápice arredondado, ca $0,5 \mathrm{~cm}$ compr., lábio inferior 3-lobado, lobos semelhantes, palato papiloso; calcar cilíndrico, ápice agudo, maior que lábio inferior da corola. Fruto não visto.

Material examinado: Cachoeira dos Macacos, 6.II.2004, fl., R.C. Forzza et al. 2698 (K, RB).

Utricularia amethystina ocorre por toda América tropical e subtropical. No Brasil é registrada no Norte, Nordeste, Sudeste e Centro-Oeste (Taylor 1989, Fromm-Trinta 1996, Miranda \& Rivadavia 2012). Vegeta em brejos, campos úmidos e arenosos, entre cerrado e floresta de galeria (Fromm-Trinta 1996), sendo mais tolerante à sombra do que a maioria das outras Utricularia (Taylor 1989). No PEIB foi coletada apenas uma vez ocorrendo em solo úmido, arenoso, entre gramíneas.
Utricularia amethystina é uma das espécies de maior variação morfológica dentro do gênero (Taylor 1989, Silva et al. 2011). Taylor (1989) indica que a grande variação morfológica da espécie consiste na presença e densidade de glândulas no cálice, tamanho do pedicelo e comprimento dos lobos do lábio inferior da corola, além da variação de coloração da corola, que pode ser roxa, branca ou amarela. Afirma, porém que existe uma gama contínua de formas intermediárias, assegurando a unidade da espécie.

2.2. Utricularia laciniata A.St.-Hil. \& Girard, Compte Rend. Hebd., Séances Acad. Sci. 7: 870. 1838.

Fig. 1. $r-x$

Erva delgada, 6-9 cm alt. Folhas não observadas. Escapo glabro em toda extensão, ca. 0,3 $\mathrm{mm}$ diam. Escamas da base do escapo numerosas, basifixas, 0,5-1 mm compr., de margem fortemente fimbriada; as escamas da porção superior tridentadas ou quase inteiras. Brácteas basifixas, ovadas, 0,5-1 $\mathrm{mm}$ compr., ápice agudo, margem inteira ou levemente dentada. Brácteas subentendendo uma gema em dormência ou abortada. Bractéolas 2, similares às brácteas, mais estreitas. Inflorescência ereta, simples, 2-flora. Flores com lobos do cálice desiguais, lobo superior ovado, ápice agudo, margem esparsamente dentada, $2 \mathrm{~mm}$ compr., nervuras não definidas, lobo inferior mais estreito, oblongo, ápice bífido; corola 5-8 mm compr., lilás a roxa, mácula central alva ou amarela na base do lábio inferior; lábio superior inteiro, obovado, inferior amplamente orbiculado, $5 \mathrm{~mm}$ compr., geralmente inteiro, raro 3 ou 4-lobado; calcar maior ou igual ao lábio inferior da corola. Fruto globoso, ca. $2 \mathrm{~mm}$ diam., deiscência irregular.

Material examinado: próximo à Janela do Céu, 5.Il.2004, fl., R.C. Forzza et al. 2668 (RB).

Utricularia laciniata ocorre por toda a América do Sul e no Brasil é registrada apenas para Goiás e Minas Gerais (Taylor 1989, Miranda \& Rivadavia 2012). Vegeta em solos arenosos e úmidos, em campos úmidos, pântanos e campos rupestres (Fromm-Trinta 1996). No PEIB foi encontrada em apenas uma localidade ocorrendo em solo arenoso e úmido. Floresce de janeiro a maio (Taylor 1989). Utricularia laciniata é comumente confundida com $U$. purpureocaerulea A.St.-Hil. \& Girard, da qual pode ser distinta pelas escamas que são fortemente fimbriadas na porção basal do escapo.

2.3. Utricularia nana A.St.-Hil. \& Girard, Compte Rend. Hebd., Séances Acad. Sci. 7: 869. 1838.

Fig. 2. $a-b$

Erva 0,8-2,5 cm alt., anual, terrestre. Folhas 5$10 \times 0,5-1 \mathrm{~mm}$, lanceoladas a linear, uninérvias. Inflorescência 1-flora. Escapo ereto, cilíndrico, glabro, 
$1 \mathrm{~mm}$ diam. Escama, quando presente 1, deltoide, $1 \mathrm{x}$ $0,5 \mathrm{~mm}$. Brácteas e bractéolas basifixas, ovais, 0,5-1,5 x 0,5-1 mm em 2 a 4 verticilos. Inflorescência ereta, solitária. Flor alva a amarela, pedicelo reduzido ou ausente; cálice desigual, lobo superior fortemente nervado, linear a ovado, $2 \times 1 \mathrm{~mm}$, ápice obtuso, lobo inferior ovado-deltoide, $2-2,5 \times 1,5-2 \mathrm{~mm}$, ápice obtuso; corola ca. $5 \mathrm{~mm}$ compr., lábio superior maior que sépala superior, ca. $3 \mathrm{~mm}$ compr., ápice ligeiramente 2-lobado, lábio inferior ca. $2 \mathrm{~mm}$ compr., fortemente 3-lobado, transversalmente elíptico, ca. 3 $\mathrm{mm}$ larg., calcar 1,5 mm compr., subulado, menor que o lábio inferior da corola, ápice obtuso. Fruto não observado.

Material examinado: trilha entre o Lago dos Espelhos e Monjolinho, 18.IX.2007, fl., fr., B. Sette-Camara et al. 2 (RB).

Utricularia nana ocorre por toda América do Sul e no Brasil é registrada do Pará até o Paraná (Taylor 1989, Miranda \& Rivadavia 2012). Vegeta em mata de restinga, floresta pluvial, geralmente em lugares alagadiços ou próximos a córregos e nascentes (Corrêa \& Mamede 2002). No PEIB foi coletada em campo graminoso encharcado. Floresce quase o ano inteiro (Fromm-Trinta 2004).

Utricularia nana é caracterizada por apresentar escapo de grande diâmetro se comparado com o porte da planta e calcar maior que o lábio inferior da corola, com a qual forma ângulo de $90^{\circ}$ (Taylor 1989). No material de Ibitipoca a proporção do escapo-porte é seguida, porém o calcar é muito reduzido, menor que o lábio inferior da corola. Também a organização das brácteas e bractéolas é diferente das demais espécies, não apresentando a disposição de uma bráctea e duas bractéolas no mesmo verticilo floral, mas sim 2-4 brácteas em verticilos diferentes.

2.4. Utricularia neottioides A.St.-Hil. \& Girard, Compt. Rend., Hebd. Séances Acad. Sci. 7: 869. 1838.

Fig. 2. c-f; 4 c-d

Erva delgada, $6-18 \mathrm{~cm}$ alt. Estolões numerosos, entrelaçados, $0,5 \mathrm{~mm}$ espessura. Folhas filiformes, ramificadas, partindo dos estolões e das axilas das escamas inferiores do escapo. Escapo tereto, glabro, mais ou menos flexuoso, ca. $0,5 \mathrm{~mm}$ diam. Escamas basisolutas 1,5-2,0 X 0,5 mm, numerosas, ovais. Brácteas basisolutas, ovais, 2,0-2,5 $X \quad 0,5 \mathrm{~mm}$. Bractéolas ausentes. Inflorescência racemosas, ca. 10 flores, ereta, densamente cespitosa. Flores alvas a creme, 4-6 mm compr.; pedicelo 1,5-3 mm compr., glabro, tereto; lobos do cálice bastante desiguais, ovados; corola com lábio superior inteiro, carenado ca. 2,5 x 3,5 mm compr., lábio inferior, 3-lobado, ca. $3 \times 4 \mathrm{~mm}$, lacínios iguais, 2 x $1 \mathrm{~mm}$; calcar menor que o lábio inferior da corola, ca. 1,5 mm compr., ápice arredondado curvado para cima. Fruto cápsula 1-1,5 cm compr., elipsoide, marrom, deiscência por um poro oblongo ventral.

Material examinado: 23.VII.1982, fr., R. Mello-Silva s.n. (CESJ 6962); 3.V.1952, fl., fr., L. Krieger s.n. (CESJ 16536); ribeirão do Salto, abaixo da Prainha, 24.VII.1982. fl., R. Mello-Silva s.n. (CESJ 6963); 12.IX.1991, fl., S.M.S. Verardo s.n. (CESJ 25365); M. Eiterer \& G.S. Freitas 64 (CESJ); Cascatinha, 11.III.2004, fl., R.C. Forzza et al. 3217 (K, MBM, RB, SPF); Janela do Céu, 17.III.2005, fl., R. DiasMelo et al. 239 (K, RB).

Utricularia neottioides ocorre na Venezuela, Colômbia e Bolívia e no Brasil é registrada para todas as regiões, exceto a Sul (Fromm-Trinta 2004, Miranda \& Rivadavia 2012). Classificada como reófita, esta espécie cresce em corredeiras e cascatas de rios e riachos e não ocorre em poças estáticas (Taylor 1989, Silva et al. 2011). No PEIB todas as populações encontram-se agarradas às pedras, dentro de cachoeiras (Fig. 4c). Floresce quase o ano todo, quando o nível dos riachos começa a baixar (FrommTrinta 2004, Silva 2009).

2.5. Utricularia nervosa G. Weber ex Benj. in Mart., Fl. bras. 10: 247. 1847.

Fig. 2. $g-k$

Erva terrestre, $10-36 \mathrm{~cm}$ alt. Folhas não vistas.; escapo tereto, 0,5-1 $\mathrm{mm}$ diam., pubescente no terço inferior, glabro no terço superior. Escamas basisolutas, ca. $1 \times 0,5 \mathrm{~mm}$, lineares a ligeiramente ovadas, na porção basal do escapo; poucas 1,5-2 x 1$1,5 \mathrm{~mm}$, linear a romboidais, com extremidades arredondadas, na porção mediana do escapo. Brácteas basisolutas, amplexicaules, iguais às escamas da porção mediana. Bractéolas ausentes. Inflorescência racemosa, de eixo longo e flexuoso, 4flora. Flores amarelas, ca. $1 \mathrm{~cm}$ compr.; pedicelos $0,8-$ $2 \mathrm{~cm}$ compr.; lobos do cálice sub-iguais, lobo superior 1,5-2 x 1,5 mm e inferior 1,5-2 x $1 \mathrm{~mm}$, circulares a ovado, ápice arredondado, nervos inconspícuos não atingindo a margem; lábio superior da corola inteiro, ca. $4 \mathrm{~mm}$ compr.; largamente ovado, ápice arredondado, lábio inferior 3-lobado, ca. $6 \mathrm{~mm}$ compr., transversalmente oblíquo, giba bilobada; calcar subulado, maior que o lábio inferior da corola, ápice agudo ou levemente 2-dentado. Fruto não visto. 
Lentibulariaceae no Parque Estadual do Ibitipoca, Minas Gerais

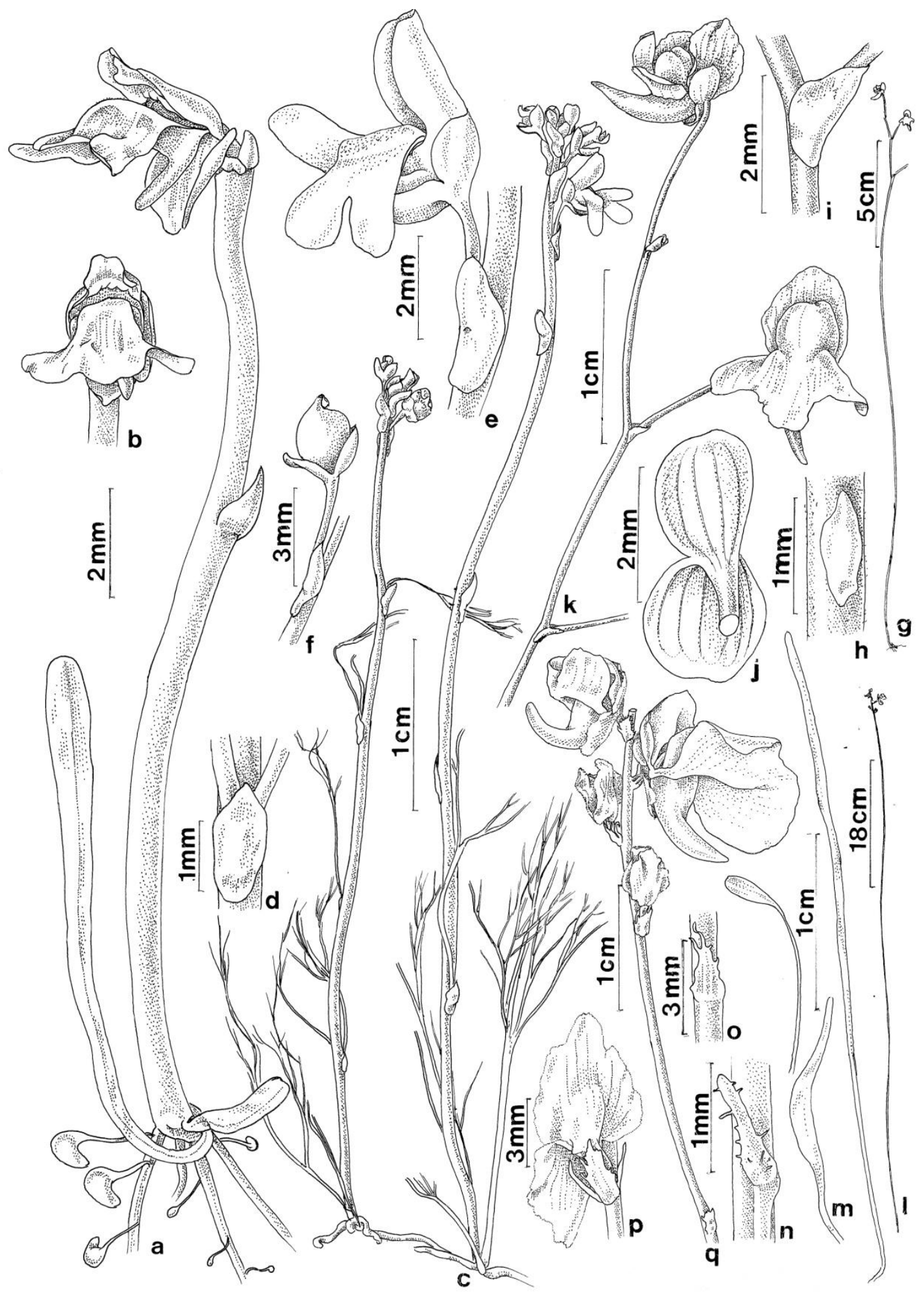

Fig. 2. a-b. Utricularia nana. a. Hábito. b. Corola em vista frontal. c-f. U. neottioides. c. Hábito. d. Escama. e. Bráctea e corola em vista lateral. f. Fruto. g-k. U. nervosa. g. Hábito. h. Escama. i. Bráctea. j. Cálice. k. Inflorescência, detalhe da corola em vista frontal e lateral. I-q. U. praelonga. I. Hábito. m. Folhas (espatulada, lanceolada e linear). n. Escama basal o. Escama apical. p. Bráctea, bractéolas e cálice. q. Inflorescência, detalhe da corola em vista lateral. (a-b Sette-Camara 2; c-f Forzza 3217; g-k Rivadavia 503; I-q Forzza 2658). 
Material examinado: rio do Salto, $500 \mathrm{~m}$ acima da Prainha, 29.X.1995, fl., F. Rivadavia \& L.R. Padovese 503 (SPF). Material adic
Toledo 565 (RB).

Utricularia nervosa ocorre na Guiana, Venezuela, Colômbia, Argentina, Paraguai e Brasil, desde o Amazonas até Santa Catarina (Taylor 1989, Miranda \& Rivadavia 2012). Vegeta em florestas, cerrado e campo rupestre, em solos encharcados, brejos e margens de córregos (Corrêa \& Mamede 2002, Silva 2009). No PEIB foi coletada crescendo entre gramíneas, próximo ao rio do Salto. Floresce em todos os meses do ano (Taylor 1989).

Utricularia nervosa é semelhante a U. subulata, podendo ser diferenciada por possuir porte maior e pedicelos mais longos. Também se assemelha a $U$. triloba, mas esta possui as nervuras das sépalas proeminentes, estendendo-se até o ápice, enquanto que $U$. nervosa possui nervuras inconspícuas, que não se estendem até o ápice.

2.6. Utricularia praelonga A.St.-Hil. \& Girard, Compt. Rend. Hebd, Séances Acad. Sci. 7: 870. 1838.

Fig. 2. I-q

Erva robusta, $40-70 \mathrm{~cm}$ alt. Folhas trimórficas: espatuladas, pecíolo ca. $2 \mathrm{~cm}$ compr., lâmina ca. 0,5 cm compr.; lanceolada, ca. 2,5 cm compr. e lineares ca. $9 \mathrm{~cm}$ compr. Escapo 1-2 mm diam., marrom a negro in sicco; glabro a esparsamente híspido na base. Escamas basifixas, lanceoladas, escamas da porção basal do escapo levemente inteiras, marrons a negras in sicco, 2-3 mm compr, escamas da porção mediana laciniadas, maiores. Brácteas basifixas, ca. 2 $\mathrm{mm}$ compr. amarelo-esverdeadas, ovadas, profundamente laciniadas, lacínios vináceos; 2 bractéolas inteiras, basifixas, ca. $2 \mathrm{~mm}$ compr. lineares, amarelo-esverdeadas, ápice vináceo. Inflorescência ereta, racemosa, 3-8 flores. Flores amarelas, $2-5 \mathrm{~cm}$ compr. lobos do cálice amarelos in sicco com margem dentada, lobo maior $4-5 \mathrm{~mm}$ com, lobo menor ca. $3 \mathrm{~mm}$ compr., largamente ovado, piloso; corola 1-1,5 cm compr., amarela, lábio superior oval, ápice arredondado, inferior elíptico; calcar estreitamente cônico, maior ou igual ao comprimento da corola, ápice agudo, levemente curvo. Fruto não visto.

Material examinado: trilha para o Cruzeiro, após a Lombada, 5.Il.2004, fl., R.C. Forzza et al. 2658 (RB); trilha Monjolinho-Lagoa Seca, 18.I.2005, fl., R.C. Forzza et al. 3915 (K, MBM, RB, SPF).

Utricularia praelonga ocorre no Paraguai, Argentina e Brasil, nos estados da Bahia, Goiás, Minas Gerais, Rio de Janeiro, São Paulo, Paraná e Santa Catarina (Miranda \& Rivadavia 2012). Vegeta em campos naturais alagados, florestas de galeria e brejos, da Floresta Atlântica, cerrado e campos rupestres (Corrêa \& Mamede 2002, Fromm-Trinta 2004). No PEIB foi coletada em solos úmidos entre gramíneas. Floresce e frutifica de outubro a abril (Fromm-Trinta 1996), porém no PEIB floresce em janeiro e fevereiro.

2.7. Utricularia pubescens Sm., Rees. Cyclop. 37: 53. 1819.

Fig. 3. a-e

Erva 9-11 cm alt. Folhas verdes in sicco, orbiculares ou subrotundas, peltadas, 2-5 mm diam., glabras. Escapo glanduloso. Escamas ovadas a oblongo-ovadas, ca. 1,2 x 0,5-1 mm. Brácteas e bractéolas basisoluta, soldadas próximo à base, mais largas que as escamas. Inflorescência ereta e simples, 1-flora. Flores roxas, com mácula amarela na base do labelo inferior, ca. $1 \mathrm{~cm}$ compr., pedicelo ca. 0,4 mm compr.; lobos do cálice sub-iguais, $2 \times 1,5$ $\mathrm{mm}$, glabros a pubescentes; lábio superior inteiro ou quase cordado, lábio inferior oval, arredondado; calcar $0,7 \mathrm{~mm}$, maior que lábio inferior da corola. Fruto não visto.

Material examinado: $200 \mathrm{~m}$ acima da Prainha, 28.X.1995, fl., F. Rivadavia \& L.R. Padovese 498 (SPF); entre Janela do Céu e Cachoeirinha, 24.XI.2001, fl., F. Rivadavia 1328 (SPF).

Material adicional: Rio de Janeiro. Itatiaia: base das Agulhas Negras, beira do ribeirão das Flores, Ill.1937, fl., A.C. Brade 15641 (RB); idem, Planalto, 1.III.1950, fl., A.C. Brade 20226 (RB).

Utricularia pubescens ocorre na Índia, África e Américas do Sul e Central. No Brasil é registrada em Roraima, Amazonas, Ceará, Mato Grosso, Goiás, Minas Gerais, Rio de Janeiro e São Paulo (Taylor 1989, Miranda \& Rivadavia 2012). Vegeta em campos rupestres e regiões expostas dentro de matas, sempre em locais brejosos (Silva 2009). No PEIB cresce em solo arenoso na beira do rio, junto com Drosera villosa A.St.-Hil., $U$. nervosa e $U$. reniformis. Floresce ao longo do ano todo, em geral no início ou fim das estações chuvosas (Taylor 1989).

2.8. Utricularia reniformis A.St.-Hil., Voy. Rio de Janeiro \& Minas Gerais 1: 244. 1830.

Fig. 3. f-k; 4. a-b

Erva terrestre, ou epífita crescendo em bromélia, 36-67 cm alt. Folhas numerosas, reniformes, membranáceas, discolores, opacas em ambas as faces, verdes; lâmina 2,5-9,0 X 3,5-10 cm, pecíolos cilíndricos $13-30 \times 0,1-0,3 \mathrm{~cm}$, glabros. Escapo branco na base, vináceo no terço inferior e o restante verde, 1-6 mm diam., glabro, cilíndrico, escamas basifixas $0,5-1,0 \times 0,2-0,3 \mathrm{~cm}$, inteiras marrons a verdes in sicco, elíptico-lanceoladas, ápice 


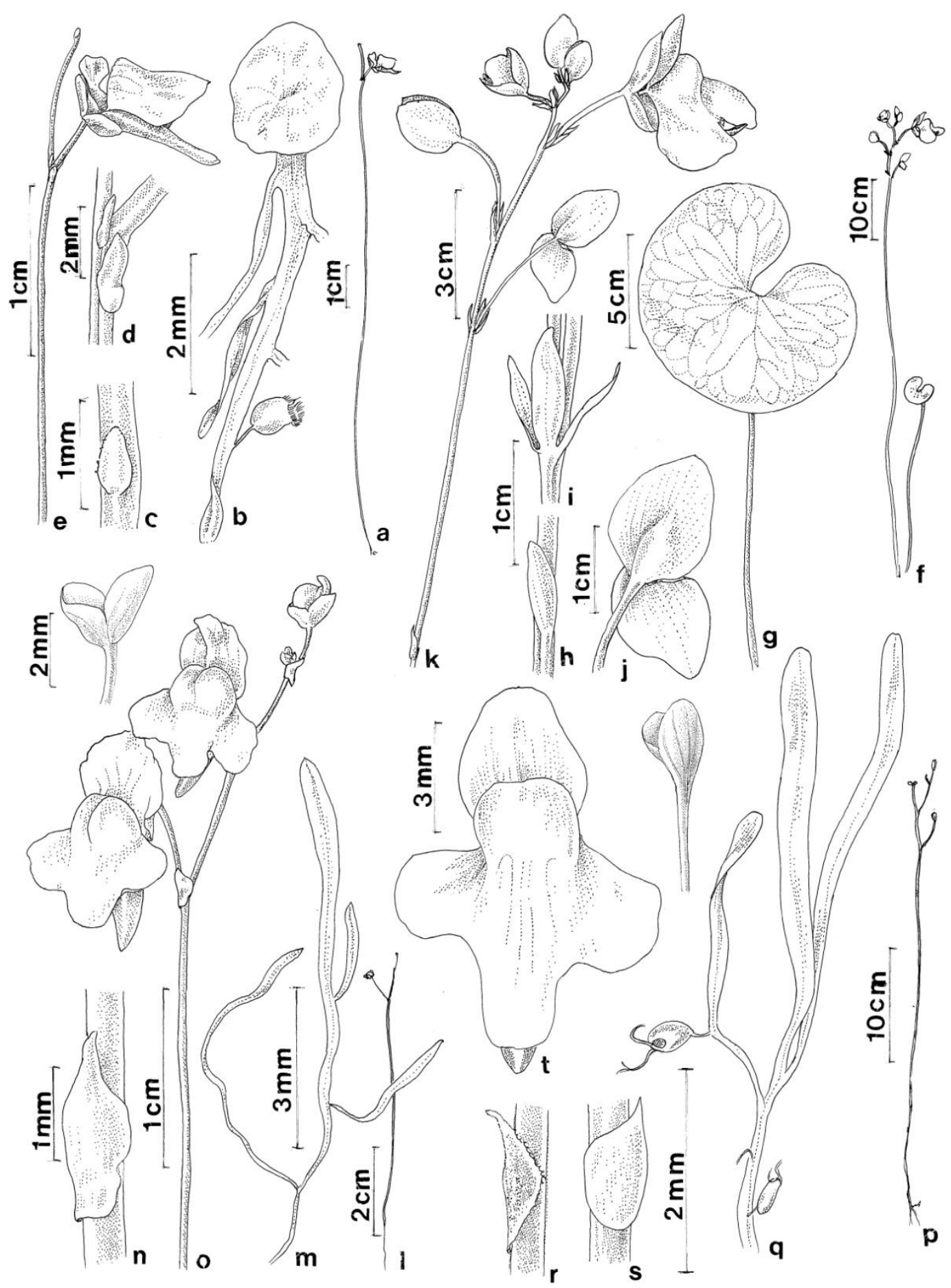

Fig. 3. a-e. Utricularia pubescens. a. Hábito. b. Folha peltada com utrículo. c. Escama basal. d. Bráctea e bractéolas. e. Inflorescência, detalhe da corola em vista lateral. f-k. U. reniformis. f. Hábito. g. Folha reniforme. h. Escama. i. Bráctea e bractéolas. j. Cálice. k. Inflorescência, detalhe dos botões e corola em vista lateral. I-o. U. subulata. I. Hábito. m. Folhas. n. Escamas. o. Inflorescência, detalhe corola em vista frontal. p-t. U. triloba. p. Hábito. q. Folhas com utrículos. r. Escama basal. s. Bráctea. t. Flor em vista frontal. (a-e Rivadavia 1328; f-k Sette-Camara 3; I-o Forzza 3114; p-t Krieger s.n. CESJ 24298). 
agudo a obtuso. Brácteas basifixas, 0,5-1 x 0,2-0,3 $\mathrm{cm}$, elíptico-lanceoladas, ápice agudo a obtuso. Bractéolas 2, livres, basifixas, pouco menores que as brácteas, estreitamente elípticas. Inflorescência racemosa, ereta, 3-5 flora. Flores lilases, giba 2lobada com máculas amarelas, $2-4 \mathrm{~cm}$ compr., pedicelos 0,6-3,5 cm compr., achatados, glabros; lobos do cálice 0,8-1,5 x 0,5-1 cm, desiguais, ovados, multinervados, base arredondada, lobo superior ovallanceolado, lobo inferior ligeiramente menor, oval; lábio superior da corola oval, ápice arredondado a truncado, lábio inferior transversalmente oblongo, 2lobado, lobos laterais redondos, lobo mediano bem menor ou obsoleto, semicircular; calcar estreitamente cilíndrico, pouco maior que o lábio inferior. Fruto não visto.

Material examinado: Cachoeira dos Macacos, 18.VII.1992, fl., F. Rivadavia 142 (SPF, RB); trilha para o Pico do Pião, 10.III.2004, fl., R.C. Forzza et al. 3095 (K, RB); trilha Monjolinho-Pião, 28.X.2004, fl., R.C. Forzza et al. 3599 (NY, RB, SPF); caminho para Prainha, 1.X.1970, fl., P.I.S. Braga et al. 1923 (RB, SPF); Lago dos Espelhos, 18.IX.2007, fl., $B$. Sette-Camara et al. 3 (K, RB).

Utricularia reniformis é endêmica do Domínio Atlântico, ocorrendo em todos os estados das regiões Sudeste e Sul (Miranda \& Rivadavia 2012). Vegeta em campos graminosos encharcados, rochas úmidas ou em tanques de Bromeliaceae. No PEIB pode ser encontrada dentro de córregos, próxima à cursos d'água ou em rochas muito úmidas entre Sphagnum. Floresce entre setembro e março (Taylor 1989).

Utricularia reniformis apresenta uma enorme variação no tamanho, sendo os maiores indivíduos similares a $U$. nelumbifolia Gardner, que pode ser diferenciada pelas folhas orbiculares, peltadas e bractéolas menores. Estas duas espécies e $U$. humboldtii Schomb. são as únicas dentro do gênero que podem ocorrer em tanques de bromélias, especificamente Vriesea e Alcantarea. Apresentam estolão robusto que permite o armazenamento de nutrientes garantindo a resistência da planta em épocas de enchentes/cheia (Adlassnig et al. 2005).

\subsection{Utricularia subulata L., Sp. PI. 1:18. 1753.}

Fig. 3. I-O

Erva delgada $3,5-9 \mathrm{~cm}$ alt. Folhas verdes in sicco filiformes, 1-nervadas, 0,5-1,5 cm compr., ápice subagudo portando utrículos. Escapo tereto, ca. $1 \mathrm{~mm}$ diam., densamente glanduloso e papiloso na base, vináceo a marrom-claro por toda extensão. Escamas basisolutas na região pilosa do escapo, 1,5-2 mm compr., cerca de 4, romboidais, de margem dentada; escamas basifixas, amplexicaule ou basisolutas na porção mediana do escapo, ca. 1 × 0,5 mm, romboidais, marrons, glabras. Brácteas basisolutas, amplexicaule, 1-1,5 mm compr., romboidais, com extremidades arredondadas. Bractéolas ausentes. Inflorescência ereta, simples. Flores amarelas, pedicelos 0,5-1 (-1,5) mm compr., lobos do cálice subiguais, largamente ovados a circular, 1-2 mm compr., nervação não atingindo a margem; corola ca. $1 \mathrm{~cm}$ compr., lábio superior inteiro, ca. $3 \mathrm{~mm}$ compr., ovado, lábio inferior profundamente 3-lobado, romboidal, ca. 7 x $7 \mathrm{~mm}$, com base bilobada proeminente; calcar subulado ou estreitamente cilíndrico, do mesmo tamanho do lábio inferior, ápice agudo ou bífido. Fruto cápsula globosa, 2-3 mm diam.

Material examinado: campo entre Gruta dos Viajantes e Pico do Pião, 10.III.2004, fl., R.C. Forzza et al. 3114 (K, RB); trilha Lagoa Seca-Janela do Céu, 30.III.2004, fl., R. Dias-Melo et al. 179 (K, RB); Cachoeira dos Macacos, 26.X.2004, fl. e fr., B.R. Silva et al. 1348 (RB).

Utricularia subulata possui distribuição pantropical e no Brasil ocorre do Amazonas ao Rio Grande do Sul (Taylor 1989, Miranda \& Rivadavia 2012). Vegeta em solos arenosos e úmidos, savanas, banhados, pântanos, margens de córregos e terrenos turfosos de restingas (Fromm-Trinta 1996). No PEIB foi encontrada próximo de cursos d'água, em solo arenoso, úmido entre gramíneas. Floresce durante todo o ano, exceto nas épocas secas (Taylor 1989).

2.10. Utricularia triloba Benj. in Mart., FI. bras.10: 248. 1847.

Fig. 3. p-t

Erva delgada, 4,5-10 cm alt. Folhas numerosas filiformes, 1-nervada, 3-5 mm compr., diáfanas a esverdeadas in sicco. Escapo papiloso no terço inferior e glabro na porção restante. Escamas basiolutas, elípticas, as basais mais longas, quase fusiformes, de margem ciliada, 1-1,5 mm compr., as mais apicais losangulares, inteiras. Brácteas basisolutas, amplexicaules, 1-1,5 mm compr., elípticas, ápice agudo, bractéolas ausentes. Inflorescência ereta, até 8 flores. Flores amarelas; pedicelos glabros, cilíndricos, 0,7-1 cm compr., lobos do cálice sub-iguais, 1-2 mm compr., ovais, fortemente 5-nervados, ápice agudo; corola 0,7-1 cm compr., lábio superior amplo, inferior 3-lobado, 5-8 mm compr., lobo mediano maior que os laterais; calcar igual ou maior que o lábio inferior da corola, extremidade ligeiramente bífida. Fruto cápsula globosa, deiscência irregular, $2 \mathrm{~mm}$ diam.

Material examinado: sem local, 6.II.1989, fl. e fr., $L$. Krieger s.n. (CESJ 24298).

Material adicional: Bahia. Entre Alcobaça e Caravelas, rodovia 101, 17.I.1977, fl., R.M. Harley 18034 (RB). Minas Gerais. Diamantina, subida para o Cruzeiro, 10.I.963., fl., A.P. Duarte 7959 (RB).

Utricularia triloba ocorre nas Américas Central e do Sul e no Brasil de Roraima a Santa Catarina (Taylor 1989, Miranda \& Rivadavia 2012). Vegeta em campos de altitude, campos rupestres, lugares úmidos, brejos, restinga e beira de rios (Fromm-Trinta 
Lentibulariaceae no Parque Estadual do Ibitipoca, Minas Gerais
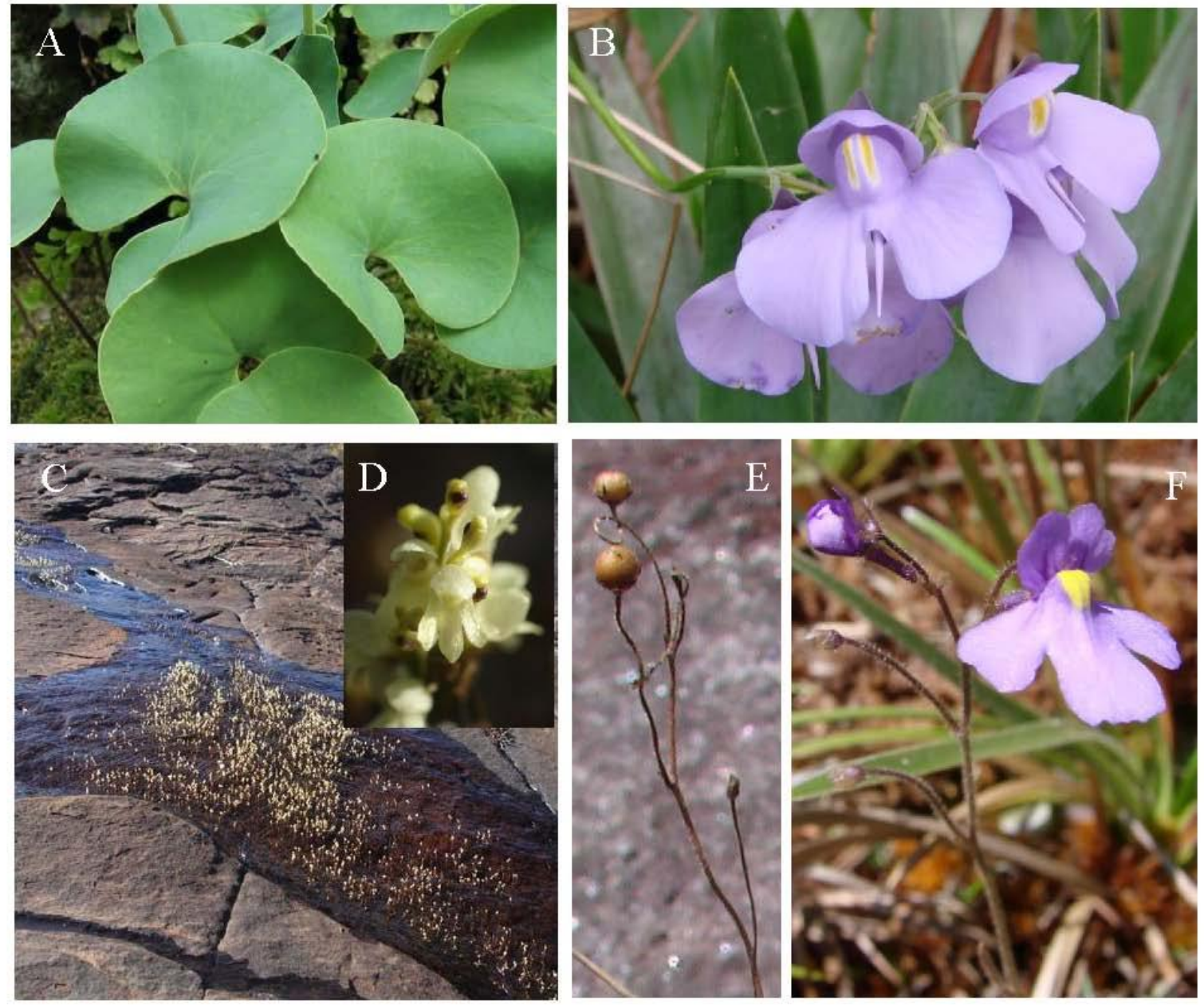

Fig. 4. A-B. Utricularia reniformis: A. folhas, B. flores. C-D. U. neottioides: C. habitat, D. flores. E-F. G. violacea: E. fruto, F. flor. 
2004). Floresce ao longo de todo o ano, exceto nas épocas secas (Taylor 1989).

\section{Agradecimentos}

Os autores agradecem ao IEF-MG e à administração do Parque por todo apoio durante os trabalhos de campo. A Claudia Bove, Marcus Nadruz e dois assessores anônimos pelas sugestões. Aos curadores dos herbários citados pelo empréstimo dos materiais. As ilustrações foram confeccionadas por Paulo Ormindo. Beatriz Sette teve bolsa PIBIC/CNPq/JBRJ e Rafaela Campostrini Forzza é bolsista de Produtividade em Pesquisa do CNPq.

\section{Referências}

ADLASSNIG, W., PEROUTKA, M., LAMBERS, H. \& LICHTSCHEIDL, I.K. 2005. The roots of carnivorous plants. Plant and Soil 274: 127-140.

BARTHLOTT, W., POREMBSKI, S., SEINE, R. \& THEISEN, I. 2004. Karnivoren. Biologie und Kultur fleischfressender Pflanzen. Ulmer. Stuttgart.

CETEC. 1983. Diagnóstico ambiental de Minas Gerais. Belo Horizonte.

CHEEK, M. \& TAYLOR, P. 1995. Lentibulariaceae. In: Stannard, B. L.; Harley, Y. B. \& Harley, R. M. (eds.). Flora of the Pico das Almas, Chapada da Diamantina - Bahia - Brasil. Royal Botanic Gardens, Kew, p. 395-406.

CORRÊA, M. A. \& MAMEDE, M. C. H. 2002. Lentibulariaceae. In: M.G.L. Wanderley, G.J. Shepherd \& A.M. Giulietti (coord.). Flora fanerogâmica do Estado de São Paulo. RIMA, FAPESP. São Paulo, vol. 2., p. 141-154.

FISCHER, E., POREMBSKI, S. \& BARTHLOTT, W. 2000. Revision of the genus Genlisea (Lentibulariaceae) in Africa and Madagascar with notes on ecology and phytogeography. Nord. J. Bot. 20(3): 291-318.

FLEISCHMANN, A., RIVADAVIa, F., GONELLA, P.M. \& HEUBL, G. 2011. A revision of Genlisea subgenus Tayloria (Lentibulariaceae). Phytotaxa 33: 1-40.

FONT QUER, P. 1989. Diccionario de Botánica. Editorial Labor. Barcelona.

FROMM-TRINTA, E. 1977. Tayloria Fromm-Trinta - Nova seção do gênero Genlisea A.St.-Hil. (Lentibulariaceae). Bol. Mus. Nac. Rio de J. Museu Nacional 44: 1-4.

FROMM-TRINTA, E. 1979. Revisão das espécies do gênero Genlisea A.St.-Hil. (Lentibulariaceae) das regiões sudeste e sul do Brasil. Rodriguesia 31(49): 17-139.
FROMM-TRINTA, E. 1996. Flora da Serra do Cipó, Minas Gerais: Lentibulariaceae. Bol. Bot. Univ. São Paulo 15: 105-118.

FROMM-TRINTA, E. 2004. Flora de Grão-Mogol, Minas Gerais: Lentibulariaceae. Bol. Bot. Univ. São Paulo 22(2): 267-271.

HARLEY, R. M. \& SIMMONS, N. A. 1986. Florula do Mucugê, Chapada Diamantina, Bahia, Brasil. Royal Botanical Gardens. Kew.

HOLMGREN, P., HOLMGREN, N.H. \& BARNETT, L. 1990. Index herbariorum. 8th ed. New York Botanical Garden. New York.

JUNIPER, B. E., ROBINS, R. J. \& JOEL, D. M. 1989. The carnivorous plants. Academic Press. London.

MENINI NETO, L., ALVES, R.J.V., BARROS, F. \& FORZZA, R.C. 2007a. Orchidaceae do Parque Estadual de Ibitipoca, MG, Brasil. Acta Bot. Bras. 21(3): 687-696.

MENINI NETO, L., ALVES, R.J.V. \& FORZZA, R.C. 2007b. A subtribo Pleurothallidinae (Orchidaceae) no Parque Estadual de Ibitipoca, Minas Gerais, Brasil. Bol. Bot. Univ. São Paulo 25(2): 253-278.

MIRANDA, V.F.O. \& RIVADAVIA, F. 2012. Lentibulariaceae in Lista de Espécies da Flora do Brasil. Jardim Botânico do Rio de Janeiro. (http://floradobrasil.jbrj.gov.br/2012/ FB000146).

SALIMENA 2000. Ecoturismo x conservação dos campos rupestres. In: Tópicos atuais em botânica: Palestras convidadas do $51^{\circ}$ Congresso Nacional de Botânica, Brasília. pp. 343-347.

SILVA, N.G. 2009. Droseraceae Salisb. e Lentibulariaceae Rich. da Serra de São José, Minas Gerais, Brasil. Dissertação de Mestrado. Universidade Federal do Rio de Janeiro.

SILVA, N.G., ALVES, R.J.V., PEREIRA, J.F. \& RIVADAVIA, F. 2011. Lentibulariaceae, Serra de São José, Minas Gerais, Brazil. Check List 7(2): 120-127.

STEARN, W.T. 1992. Botanical Latin. David \& Charles Newton Abbot. England.

TAYLOR, P. 1989. The Genus Utricularia - a taxonomic monograph. Kew Bulletin Additional Series XIV. Royal Botanical Garden. Kew.

TAYLOR, P. 1991. The Genus Genlisea. Carnivorous Plant Newsletter 20: 20-26.

TAYLOR, P. 2003. Lentibulariaceae. In: D.C. Zappi, E. Lucas, B.L. Stannard, E.N. Lughadha, J.R. Pirani, L.P. Queiroz, S. Atkins, D.J.N. Hind, A.M. Giulietti, R.M. Harley \& A.M. Carvalho. Lista das plantas vasculares de Catolés, Chapada Diamantina, Bahia, Brasil. Bol. Bot. Univ. São Paulo 21(2): 377. 
Bromeliaceae na APA da Pedra Branca, Caldas, Minas Gerais

\section{Lista de exsicatas}

Brade 156412 (2.7), 20226 (2.7).

Braga 1923 (2.8).

Confúcio s.n. CESJ 9385 (1.2).

Damazio s.n. RB 112381 (1.1).

Dias-Melo 179 (2.9), 239 (2.4).

Duarte 2752 (1.1), 7959 (2.10).

Eiterer 64 (2.4).

Forzza 2658 (2.6), 2668 (2.2), 2698 (2.1), 3095 (2.8), 3096

(1.2), 3114 (2.9), 3217 (2.4), 3598 (1.2), 3599 (2.8), 3915

(2.6).

Harley 18034 (2.10).

Krieger s.n. CESJ 9474 (1.1), CESJ 14596 (1.2); CESJ 16536 (2.4), CESJ 16538 (1.2), CESJ 24298 (2.10).

Markgraf $10431(1.1)$.

Marquete $3117 \mathrm{a}(2.8)$

Martinelli 2667 (1.1).

Mello-Silva s.n. CESJ 6962 (2.4), CESJ 6963 (2.4).

Rivadavia 142 (2.8), 498 (2.7), 503 (2.5), 1322 (1.2), 1328 (2.7), 1952 (1.2).

Sette-Camara 1 (1.2), 2 (2.3), 3 (2.8).

Silva 1348 (2.9).

Sucre 7280 (1.2).

Toledo 565 (2.5).

Verardo s.n. CESJ 25365 (2.4). 